\title{
La imagen y su función didáctica en la educación artística
}

\author{
Luis Eduardo Motta R. *
}

Resumen: El artículo desgrana los distintos efectos que produce el actual mundo saturado de imágenes. A partir de la caracterización, despliega distintos conceptos para potenciar la enseñanza- aprendizaje a través del uso de la imagen.

Palabras clave: imagen - educación visual - sentido crítico.

[Resúmenes en inglés y portugués en la página 175]

${ }^{(*)}$ Maestro en Artes Plásticas. Doctor en Bellas, Experto Universitario en Educación Artística. Diplomado en Aptitud Pedagógica. Director de la Licenciatura en Educación Artística de UNIMINUTO.

\section{Introducción}

Vivimos en un mundo saturado de imágenes, las cuales se multiplican cada vez más de manera vertiginosa a través de los distintos medios y sistemas tecnológicos de comunicación, inundando calles, pantallas, publicaciones; prácticamente todos los espacios públicos y privados son permeados por imágenes dirigidas con la intención de estimular nuestra curiosidad o despertar en nosotros comprensión; seducirnos, indignarnos, comunicarnos, o simplemente interpelarnos de alguna manera. Las imágenes nos provocan y despiertan reacciones dejándonos sentir su poder, intensificando nuestras experiencias sensoriales como poderosos vehículos de transmisión de valores, ideas, emociones y nos dotan de información, dudas y conocimiento. A través de las imágenes construimos nuestra imaginación, proyectamos nuestros sueños, creamos nuestras fantasías y realidades convirtiéndolas en imágenes visuales, sonoras, olfativas, gustativas y táctiles; las imágenes se convierten en la base fundamental del importante andamiaje de nuestro conocimiento. Las imágenes cumplen múltiples funciones y su fuerza radica en su renovación a través de la mirada de cada espectador, sugieren distintos significados y se complementan a partir de la experiencia; obligan a variar y a complejizar su forma de mirar, dejando sentir los diferentes efectos que producen en los espectadores y sus implicaciones sociales, culturales, políticas, subjetivas e identitarias; además involucran lo racional, lo visual, lo auditivo, lo sensitivo, lo estético y lo emocional creando vínculos con las prácticas del ver y del sentir, desde donde se originan interrogantes como: ¿hasta qué punto lo visual ha adquirido 
tanta potencia e importancia en nuestro medio? ¿Todo puede o debe ser visible u observable hasta el punto de desvelar nuestra intimidad? ¿Por qué convertimos en patrones imágenes que idolatramos como salvadoras y otras que las infravaloramos señalando las culpables de grandes males? ¿Existen mecanismos que nos permitan aprender a analizar críticamente lo que vemos? ¿Podemos utilizar las imágenes con fines pedagógicos? Podríamos formularnos muchos interrogantes que pueden responderse si nos acercamos a algunos campos de conocimiento que están reflexionando sobre estas transformaciones, intentando hacer conciencia de la importancia de una educación visual que nos permita tener sentido crítico a partir de lo que vemos.

El campo de estudio de la imagen es muy amplio presentándose como interdisciplinar con varias vertientes de búsqueda y múltiples enfoques que recorren la psicología, el arte, la sociología, la antropología, la filosofía, la semiología, las nuevas tecnologías, etc.

Desde un análisis crítico de la imagen analizaremos su función didáctica a través de las distintas manifestaciones y formas de lenguaje más utilizados como el escrito o el oral y sus diversos empleos en los procesos de expresión y representación, en la relación del hombre con su entorno para entender su potencialidad en la trascendencia de la realidad, el manejo, la manipulación e interpretación de su contenido real cuyo conocimiento es preciso aprender.

Potenciar la enseñanza aprendizaje a través del uso de la imagen, en función de una propuesta basada en la construcción de ambientes pedagógicos favorables mediante la educación artística y su aplicación en el contexto social, nos permitirá plantearnos e intentar resolver múltiples interrogante frente a la imagen y su utilización didáctica: ¿Cómo se sitúa la escuela ante este mundo-imagen? ¿Es posible enseñar a aprender a mirar? ¿Cuál es la especificidad de una transmisión que toma como vehículo central las imágenes? ¿Qué agrega, quita, modifica el uso de imágenes en la educación a la hora de transmitir un mensaje? ¿Por qué La educación heredada de la imprenta y aliada del texto escrito, no considera importante la cultura visual y la señala útil solo como entretenimiento o distracción?¿Es utilizada pedagógicamente la imagen como recurso didáctico en el contexto de la escuela? Pretendemos dar respuesta a cada uno de los anteriores interrogantes ya que este documento intenta sensibilizar al público en general y en especial a los docentes, sobre la importancia del uso de la imagen como estrategia o instrumento pedagógico en cualquier campo de conocimiento;la educación artística como una nueva y eficaz propuesta metodológica puede contribuir a mejorar los procesos de enseñanza aprendizaje al interior del aula de clase, donde la imagen se tiene cada vez menos en cuenta desconociendo su importancia por parte de los docentes, en contraste con el mundo exterior donde la imagen gana cada vez más protagonismo, ocupando más espacio e importancia en el mundo de las representaciones y comunicaciones en general y especialmente a través de las nuevas tecnologías y las redes sociales indispensables en la vida de nuestros estudiantes y en la interrelación a través de instrumentos cotidianos como el teléfono celular, la tablet, los videojuego o el computador entre otros.

Nos intentaremos aproximar al papel de la imagen visual y su utilización pedagógica mediante la educación artística. El terreno es abrupto y de hecho interfiere e interactúa con las distintas disciplinas mencionadas anteriormente, no obstante, podremos darnos por satisfechos si logramos percibir algunos instantes de este elemento en perenne movimien- 
to, que permita contribuir a combatir el analfabetismo visual tan presente en nuestro sistema educativo, y desde esta perspectiva despertar inquietudes hacia nuevas posibilidades de otros aprendizajes.

Cabe destacar que estos temas son tan apasionantes como amplios y ameritan cada uno un tratado especial; en este espacio debemos limitarnos a lo justo y por lo tanto desarrollaremos cada tema lo más condensado posible, y que ojalá podamos contribuir despertando la suficiente curiosidad en el lector.

\section{La imagen como referente visual}

Las imágenes han acompañado en todo momento al ser humano y han formado parte básica en su comunicación, constituidas como elementos representativos de verdad o ilusión, magia o religión, sagradas o profanas, maléficas o buenas, han sido plasmadas a través de la historia como expresión y testimonio del desarrollo cultural y por ende constituidas como elementos fundamentales en la actividad artística; nos han permitido expresarnos y comunicarnos desde distintos campos como: el mitológico, el onírico, el mágico o el religioso, a través de mundos especiales construidos a partir de imágenes que reflejan múltiples aspectos de la realidad o la fantasía, pero en cualquier caso fundamentados en lo visual como uno de nuestros principales sentidos,desarrollado a través del aprendizaje sensorial.

La imagen desde los primeros albores de la humanidad como referente socio cultural se ha visto afectada por diversas problemáticas que sobrepasan su condición esencial y su capacidad para albergar aspectos simbólicos, expresados a través de las distintas experiencias entorno a sus posibilidades y sus problemáticas estéticas, filosóficas y de representación, creando espacios de reflexión para potenciar nuevas posibilidades entorno a las artes, la cultura y la educación dentro de los diversos contextos sociales.

El hombre posee la capacidad innata para aproximarse al mundo a través del sentido de la vista. Esto no le garantiza que lo visto corresponda fielmente con la realidad. Filósofos, psicólogos, sociólogos, artistas, comunicadores y otros teóricos de la imagen han trabajado durante años en la elaboración de una teoría perceptiva, entendida como concepto global capaz de explicar que ocurre con lo que recibe nuestro sentido de la vista cuando llega al cerebro hasta convertirse en concepto, en este sentido el campo de estudio de la imagen es muy grande y tiene varias vertientes de búsqueda desde distintas disciplinas para construir su propio cuerpo epistemológico.

Nuestro entorno visual está integrado por un mundo de sujetos que miran y objetos que son mirados, estableciéndose un juego reciproco que comprende las propiedades implícitas por el objeto y la naturaleza del sujeto observador. Ambas partes corresponden a los elementos objetivos en la experiencia perceptiva, que se desarrolla desde la perspectiva de un esquema sencillo, hasta otros de complejidad creciente mediante un proceso que nos exige, definir lo que vemos y entender porque lo vemos.

Se llegan a explicar categorías visuales y se muestran las relaciones estructurales que operan en los procesos perceptivos. Pero todo este desarrollo histórico y científico no está destinado a legislar la visión sino que posibilita la agudización de las primeras intuiciones 
visuales de cualquier sujeto que contemple el mundo a través de su visión con los sentidos agudizados en todo su potencial.

La imagen como primer referente visual se manifiesta en el arte y éste a su vez, como lo reconoce Herbert Read (1980), en el instrumento esencial en el desarrollo de la conciencia humana, de tal forma que las artes han sido los medios a través de los cuales el hombre ha podido comprender paso a paso la naturaleza de su entorno y ha podido ampliar su conciencia acerca de la naturaleza de la realidad, como puede comprobarse a través de las distintas etapas del desarrollo del hombre, desde la prehistoria hasta nuestros días.

Podemos considerar si revisamos la historia del arte desde sus inicios, que antes de la palabra fue la imagen y los primeros registros que encontramos son pictóricos, imágenes representadas de diversas formas mediante variadas técnicas; en tal sentido el arte se convierte a través de la imagen en una fuerza constante que permite descubrir formas significativas en un acto específicamente estético y que toma posesión de un segmento de lo real; lo que el hombre desea es una aprehensión más precisa de la realidad que le permita la afirmación del ser.

La imagen se ha utilizado a través de la historia con diversos fines: la encontramos representada en las distintas culturas y en todas las épocas del desarrollo de la humanidad; siempre cumpliendo una función comunicadora, estructurada a través de un sistema de códigos que se superponen, sugeridos tanto de parte del autor como del espectador en una compleja organización en la producción y la interpretación estableciendo un texto visual. Abarcan el conjunto de relaciones cromáticas y geométricas dentro de las cuales es posible la percepción visual; transitan desde los primeros albores del rayoneo o garabateo prehistórico, -similar al que descubre el niño en sus primeros balbuceos de sus experiencias gráficas-, cruzando por la interpretación de imágenes cada vez más reales hasta llegar a las complejas relaciones entre las tendencias y poéticas del arte contemporáneo.

Así, al igual que cualquier otra clase de texto, al leer una imagen ponemos en funcionamiento nuestros conocimientos y nuestras propias experiencias, ya que cuando una imagen nos interpela puede mover todo nuestro mundo interior, no solo comprometiendo nuestra cultura visual sino que en muchos casos puede constituir o poner en crisis nuestra visión del mundo, teniendo en cuenta que nuestros saberes configuran nuestras miradas. En algunos casos vemos más allá de lo que sabemos y en otras vemos distinto a como ven los otros, de tal forma que esto nos permite tener nuevas experiencias visuales con recorridos inesperados y poder proponer nuevos registros asociados a otras poéticas, tales como la intervención del silencio, la distancia y el espacio a través de la luz o la textura o simplemente la mediación de las palabras, aunque muchas veces pensemos que las palabras no alcanzan a transmitir lo que si puede la imagen. Pero también hay situaciones en que las palabras son excelentes auxiliares para entender, explicar y ayudarnos a hacer hablar a las imágenes.

\section{La imagen y su influencia en el lenguaje visual}

El mundo de la imagen y los universos artificiales dan paso a nuevas manifestaciones, transformando las expresiones artísticas y las formas de aprendizaje; las artes tales como la 
música, la plástica, el teatro, la danza, entre otras, son influidas pareciendo como si nuestra sociedad entrara en una verdadera mutación que nos empuja hacia nuevas formas de percepción, análisis y aprendizajes.

La imagen en la comunicación de masas fluye de diversas maneras en un mundo que demarca nuevos derroteros de desarrollos visuales a los cuales nos enfrentamos intentando culturalmente hacer de la imagen nuestra mejor aliada, recordándonos que si nos remontamos a la historia, nuestro primer referente es visual y que desde esta perspectiva la imagen debería ser nuestro primer instrumento didáctico en el mundo del conocimiento. A través de las distintas etapas de la historia de la humanidad, podemos comprobar cómo ha ido evolucionando la utilización de la imagen en nuestra comunicación y en nuestra forma de aprender. Los distintos testimonios artísticos como las pinturas rupestres en las cuevas de Altamira en Santander (España) o las de Lascaux (Francia), entre otras, nos recuerdan la importancia de la imagen a través de nuestra percepción; interpretadas de diversas maneras como lo menciona Herbert Read (1980): "Es aquella una forma especial de actividad por la que el hombre solo trata de llevar el mundo visible a su conciencia". Describiendo la actividad artística como la cristalización a partir del reino amorfo del sentimiento de formas significativas o simbólicas.

La Gestalt Psychologie, nos muestra la importancia de las imágenes y nos describe como se han venido desarrollando en nuestra civilización. La escuela gestáltica de pensamiento, originada en Berlín y ligada íntimamente a la herencia filosófica de Kant, pone de relieve el método fenomenológico; postula que podemos experimentar el mundo objetual solo en virtud de ciertas categorías mentales que imponemos en forma automática a la información sensorial.

A través de las primeras manifestaciones del arte rupestre hasta el arte contemporáneo podemos comprobar que las imágenes que representaban hechos sin una noción de causalidad, pero que muestran una conexión mental, aunque estén en lugares separados permitieron captarse y representarse perceptivamente por medio de un signo o una imagen que puede separase de la percepción inmediata y guardarse en la memoria.

Surge entonces el signo para establecer la sincronicidad entre hechos correspondientes de esta forma se convierte la imagen en un símbolo con significado que se desarrolla en sistemas de signos representados en escenas de danza, caza y símbolos plásticos. La imagen correspondía al deseo en su intensidad yen su realidad, mostrando una destreza progresiva que condujo luego a una estabilización de la imagen, lo reconocido fue aceptado como símbolo colectivo; se desarrollaría en otro ciclo la intuición geométrica y con ella la categoría ideal de la representación que llamamos belleza.

Surgen nuevas necesidades, entre ellas la de comunicarse y establecer para ello un lenguaje visual buscado a partir de los motivos particulares dentro de la gramática del ornamento que podría adquirir un significado simbólico, pudo haber existido una creencia mágica de signos geométricos, pero son las formas como tales, desarrolladas para establecer y fijar una nueva conciencia de la realidad que aparecen por primera vez y es el de la forma misma;la forma como una identidad imaginada y articulada, como un producto del esfuerzo constructivo, emergiendo de las actividades prácticas del hombre y en la medida que surgen se les dota de una significación estética, convirtiéndose en símbolos de sentimientos específicos. 
El sentimiento de la forma apareció en la conciencia humana representado a través de la mano, órgano que conformaba la experiencia sensorial percibida y aceptada por el ojo. Este lenguaje simbólico requería de una sensibilidad adecuada, siendo necesaria una interpretación. La representación entra en contacto directo con el símbolo geométrico abstracto y se retorna a una identificación empática con las formas vitales del entorno, volviendo al naturalismo.

La belleza se considera el segundo gran principio del arte, después de la vitalidad establecida en el periodo paleolítico. La aprehensión estética de la realidad según Herbert Read, es la coordinación de todas las facultades humanas frente a la totalidad del universo experimentado por los sentidos. La conciencia sensorial ligada al progreso de la percepción y la actividad motriz pasan por un desarrollo considerable antes que el lenguaje articulado y la representación por imágenes hagan su aparición simultánea. Sobre la actividad simbólica y el pensamiento intuitivo se hace posible una estructuración representativa del espacio haciendo necesario un desarrollo de la imaginación, entendiéndose como la capacidad de recordar imágenes y una lógica simbólica para elaborar y combinar estas imágenes a fin de que se pudiera concebir y representar el espacio en el nivel intelectual.

Primero aparece representada una etapa de empatía vital de completa mimesis; formas vegetales y animales fueron usadas como elementos decorativos con toda su vitalidad natural y poco a poco se fueron transformando estilizándose cada vez más hasta llegar a la conciencia humana como abstracciones.

Según Herbert Read primero existió la imagen y luego la idea, convirtiendo la realidad en una construcción de los sentidos, el plano cambia en la medida en que el conocimiento del entorno aumenta, la capacidad de registrar es cada vez más precisa, interviniendo en este proceso la realidad experimentada, y la representación de esa realidad no es más que la articulación del sentimiento expresado en imágenes coherentes y en lenguaje que se va consolidando en lo visual. La intención de plasmar estados de sentimientos o momentos de intuición más intensos se vuelve más compleja, dándoles una mayor unidad y significación. Las imágenes se construyen en la mente a partir de la percepción, lo que implica reconocer la función que tienen los procesos sensoriales. Reconocer la importancia de su desarrollo censo-perceptivo, tanto en el arte como en la formación de una cultura visual y la posibilidad potencializadora que estimula su construcción y evolución nos conduce a formas significativas elevando la imagen al acto estético.

Uno de los máximos exponentes que enlaza la percepción visual con el arte es Rudolf Arnheim. Éste Propone una teoría del campo visual, enunciando que cualquier configuración del estímulo luminoso que incide en la retina produce, presumiblemente, un proceso especifico en el cerebro que se origina en campos de causalidad globales y que varía en función de cualquier cambio en la distribución del estímulo.

Las imágenes no solamente son estímulos visuales o percepciones de formas, responden complementándose a través de los cinco sentidos; las hay auditivas, olfativas, gustativas y táctiles. Las imágenes se convierten en retos importantes para su análisis a través de la información percibida sensorialmente cuyo pilar fundamental proviene de la información visual. Se han realizado estudios, tratados y escrito gran cantidad de literatura sobre las imágenes y su importancia en el desarrollo sensorial, como el que comprende las imágenes olfativas maravillosamente tratado en el campo literario por Patrick Suskind en El perfume. Las 
imágenes sonoras son documentadas con amplitud en el texto de Antonio Noyola (1997) "Imágenes sonoras". Curso de Educación para los Medios (Jaime Arévalo, Coord.) México, Universidad Pedagógica Nacional. Muestran la influencia y la importancia de nuestros sentidos. Lo que podemos considerar es que unas y otras son imágenes mentales enriquecidas a través de la experiencia sensorial y así las procesamos y las comprendemos.

La imagen ante todo es testimonio y es insustituible cuando queremos mostrar las características de un objeto. Por más que nos esforcemos en describir minuciosamente cada detalle a través de nuestro lenguaje oral o escrito, nunca podremos ser tan contundentes como lo será la imagen con sus respectivas características. Otro aspecto importante es la bondad de la imagen para explicar procesos, irrepetible por ser efímeros, perennes, lentos, extraños, peligrosos o costosos. Una secuencia de fotografías para explicar la bipartición celular resulta imprescindible; un video sobre el proceso de fecundación del óvulo es muy práctico e ilustrativo; o infinidades de procesos a partir de una documentación de la imagen fija o en movimiento.

La imagen puede ser analítica cuando descompone en partes un objeto mostrando distintos aspectos de una situación o un fenómeno seleccionando elementos importantes, por ejemplo cuando muestra fragmentos de una obra de arte para explicar su composición y significado. Con sus características emotivas, provoca los deseos más íntimos y las aversiones más escondidas por su aspecto analógico, es decir, su semejanza con el mundo real. Las imágenes figurativas constituyen empatía e identificación y se convierten en reflejo emocional, en una especie de ampliación de la conciencia: la imagen de la ternura de la infancia; la falsedad o transparencia de una mirada intencionada, etc.

Otra cualidad de las imágenes es su capacidad para sintetizar procedimientos que ayudan a retenerlas en la mente y a representar conceptos, en este apartado se encuentran los símbolos gráficos, los mapas y las estadísticas; también la señales de tránsito, del metro, cuadros sinópticos o mapas.

En muchos aspectos la imagen se ha convertido en un elemento mediador entre el entorno y el individuo. El mundo no puede aprehenderse en su totalidad por la experiencia directa. Cada vez estamos más obligados a entender nuestro medio y a llegar al conocimiento a través de esa intervención de las imágenes. De ahí que éstas sean parte de los sistemas de representación que no únicamente muestran sino que se constituyen en sistemas expresivos para explicar al hombre y al universo. En este sentido la imagen se convierte en discurso, retórica y construcción subjetiva del individuo.

Para el docente el reto consiste en la construcción del discurso educativo en la imagen y con la imagen para conferirle la intencionalidad deseada, ello no puede ocurrir de forma espontánea sino a través de la reflexión crítica y contextualización del medio.

No se debe excluir la cualidad de la imagen en relación con la capacidad del ser humano para abstraer elementos del mundo real y reproducirlos después mentalmente cuando esa realidad ya no existe, y es acumulada en nuestro banco de memoria para en cualquier momento ser evocada en función de la necesidad de nuestra comunicación visual. Tal experiencia percibida por nuestros sentidos es conservada en imágenes en algún lugar de nuestro cerebro, esa capacidad de abstracción constituye la base del pensamiento estético, lógico y científico sobre los cuales se construyen los procesos de abstracción. 


\section{La imagen y su utilización pedagógica en la educación artística}

La imagen se ha multiplicado de manera vertiginosa, teniendo una acelerada utilización a través de los distintos medios y sistemas tecnológicos de comunicación y redes sociales, hasta alcanzar como lo denomina María Acaso (2009) un "hiperdesarrollo"de la imagen, obedeciendo a diversas intenciones, entre ellas su utilización con fines netamente comerciales que incrementa las nuevas sociedades de consumo.

Las tecnologías de la multiplicación y difusión utilizadas actualmente por la industria cultural audiovisual, se constituyen en factores de gran importancia en la cultura de la imagen, en las expresiones estético-artísticas, y en las redes sociales imperando sobre cualquier principio de desarrollo de la cultura de las imágenes y su desconocimiento y poco uso en sus aplicaciones didácticas.

La relación del arte a través de sus distintas épocas y en especial el análisis crítico del arte actual, la evolución de las nuevas tecnologías y su empleo en el arte contemporáneo, el desarrollo del video-arte, la fotografía digital, el computador, la video conferencia, el teléfono celular, las imágenes virtuales, las instalaciones multimedia, el internet y los nuevos soportes informáticos entre otros, se suman para dar paso a nuevas expresiones artísticas y novedosas formas de construir y representar imágenes a través de complejos canales y redes de comunicación, estimulando la complejidad de la imaginación y de lo novedoso. Con el paso del tiempo las creaciones artísticas suelen sufrir importantes cambios, por eso el arte refleja la cambiante sociedad en la que es creado;el arte es un saber que partiendo de lo cotidiano, de lo efímero o de lo permanente ha podido construir una memoria fantástica que trasciende a través del tiempo y el espacio para entender, explicar y mostrar el desarrollo humano. Pero el arte no solo es lectura que refleja la realidad, compilación de conocimientos y características destacables de una sociedad; es también posibilidades de gestar y transformar nuevas alternativas de mundo, de construir y generar nuevos conceptos y sentidos epistémicos que con posterioridad son asimilados y complementados a través de la filosofía, la ciencia y la técnica, y finalmente son asumidos por la cultura y la sociedad en general.

La educación artística se presenta como uno de los mejores medios para crear a partir de imágenes, es una respuesta a una serie de inquietudes humanas que pueden ser objetivadas conciertos fines; entre otros proporciona placer y diversión respondiendo a ciertos impulsos humanos que se traducen en la necesidad de expresar y satisfacer ideas simbólicas por medio de cualidades estéticas, emocionales, sensuales y espirituales.

Así por medio del arte conectamos la precisión de las formas, la retención de un momento bello y la fantasía interior que luego provocarán en nosotros una emoción y un significado para mostrar. En cierto sentido es como un nexo de unión entre el pasado y el futuro e, incluso, podría definirse como una proyección espiritual del presente.

El aprendizaje del arte y de la cultura en las escuelas constituye una de las estrategias didácticas más eficaces para la construcción de una ciudadanía intercultural. La presencia del arte en la educación, a través de la educación artística y de la educación por el arte, contribuye al desarrollo integral y pleno de los niños y de los jóvenes.

Por eso decimos que la educación artística es una práctica social, cultural y política que se construye en la diversidad. Debe responder a las situaciones del contexto local y global que 
la interrogan y le demandan transformaciones, que aportan a la reflexión sobre las formas de convivir y construir sentido colectivo, puesto que acontece en las relaciones humanas y en las acciones entre sujetos.

En cuanto a lo que acontece con la educación artística es una práctica, que posibilita la expresión y creación de experiencias creativas a través de los distintos lenguajes del arte; su objeto de conocimiento es la construcción e intervención de prácticas discursivas que circulan en el adentro y el afuera del escenario escolar, y está transversalizada por diversas realidades, en momentos histórico-culturales, y en contextos ideológico-políticos determinados. Por eso es prioritario que la educación artística, para el caso que nos ocupa, sea consultada y valorada como las demás asignaturas, ya que es la base de la educación; es decir, de la formación de sí mismo, del conocimiento del otro, teniendo como horizonte entre otros el sentido, la creatividad y el desarrollo sensorial dirigido hacia una educación libre, reflexiva e integral.

La imagen se aprovechó desde tiempos muy remotos para el adoctrinamiento religioso e ideológico de grandes masas de iletrados; este uso se parece al que actualmente le dan los medios de comunicación contemporáneos a la imagen publicitaria y propagandística, cuyos ámbitos, al lado del arte, han desarrollado mayormente sus aplicaciones y potencialidades. A estas alturas deberíamos preguntarnos por qué el universo de la educación ha sido el que menos forma al individuo a través de la imagen. Parece que los conceptos rígidos sobre la educación arrastran todavía el lastre de aquellos tiempos en el que el uso de la imagen se relacionaba con la ignorancia, concepción reforzada actualmente por el empleo y manipulación de los medios de comunicación utilizados de una manera casi deshumanizada al servicio de la sociedad de consumo, que gozan de una fuerte influencia ajena al mundo de la educación y mucho más relacionada con el mundo de la especulación.

A pesar de todo, el presente siglo está lleno de ejemplos muy ilustrativos sobre la importancia y la efectividad de las imágenes en procesos de formación del individuo en el arte, en las ciencias y en el desarrollo cultural. Es hasta los últimos tiempos que se le ha otorgado a la imagen el papel que le corresponde como recurso expresivo al servicio de las causas más nobles de la civilización.

Las imágenes tienen un lenguaje, transmiten mensajes, configuran nuestra cultura, la sociedad y los valores que la sostienen. Podríamos preguntarnos ¿conocemos su naturaleza, los mecanismos de significación, su funcionamiento y sus posibilidades pedagógicas?

En ocasiones acudimos a una exposición de pintura o a la proyección de un una película, y siempre podemos expresar un juicio al respecto, sin embargo no siempre podemos enunciar los argumentos que sean capaces de sustentar ese juicio al que hemos llegado.

$\mathrm{Al}$ igual que para leer los textos escritos es necesario conocer el alfabeto y sus distintos componentes como los signos de puntuación, el significado de las palabras de acuerdo con las reglas y principios de la Semiótica General, para leer las imágenes se hace necesario basarnos en la Semiótica de la Imagen. Un término importante a estos efectos fue definido desde la década del 60 como alfabetización visual. Siguiendo el criterio de la UNESCO, que reconoce el término alfabetización no solo como la capacitación básica para leer, escribir y realizar sencillos cálculos aritméticos, sino como el conjunto de capacidades intelectuales que permitan la obtención y procesamiento de la información significativa definida como alfabetización visual, específica de los medios de comunicación, al igual 
que se habla de la alfabetización en la computación, sistemas y en otras ciencias, donde es cada vez más imperativo la formación en la educación visual, entendiendo como tal el conjunto de capacidades visuales que el ser humano puede desarrollar viendo, y al mismo tiempo, integrando otras experiencias sensoriales. Considerando el desarrollo de estas capacidades como fundamental para el aprendizaje y una vez alcanzado, permite que una persona alfabetizada visualmente reconozca e interprete las acciones, objetos y símbolos visibles, naturales o artificiales que encuentre en su entorno. Empleando creativamente estas capacidades puede comunicarse con los demás disfrutando de las posibilidades de la comunicación visual.

A diferencia del lenguaje escrito donde la lectura de las unidades de la cadena lingüística se van sucediendo una tras otra, en la lectura de la imagen no existe un orden y cada observador tiene su manera de ver atendiendo a los distintos elementos como la forma, el tamaño, los colores, las texturas, la iluminación, la líneas, la composición, el volumen, que de acuerdo a su interrelación y composición ofrecen uno u otro mensaje constituyéndose en textos visuales que forman diversos componentes formales y temáticos que obedecen a reglas y estrategias precisas durante su elaboración pensando en la recepción del espectador. El texto visual está comprendido por un sistema de expresión y por un sistema de contenido, ambos son inseparables constituyéndose en una exigencia basada en el nivel de conocimiento del lector para entender el tema tratado. Es significativa la estrecha relación entre la forma y el contenido, de lo contrario no llega a comprenderse el mensaje; en la medida que el lector sea capaz de entender los signos, será capaz de comprender toda la información del mensaje a través de las imágenes.

En síntesis: si queremos trabajar pedagógicamente con imágenes debemos tener en cuenta sus atribuciones que son polisémicas, considerando que no todos vemos lo mismo cuando miramos y que estas nos afectan dependiendo el grado cultural que se posea. Se trata de enseñar y aprender a mirar analizando las imágenes desde distintos ángulos, construyéndolas y decostruyéndolas, imaginando con ellas y a partir de ellas, sin perder de vista que del mismo modo que las palabras, las imágenes son colectivas y se comparten.

Si tenemos presente que lo visible es algo que se produce, y que al lado de lo concreto habrá siempre algo invisible, constataremos que al lado de toda pedagogía de la imagen habrá también una política construyendo una mirada, y no cualquier mirada, que a través de un análisis crítico argumentativo nos permitirá comprender para poder soñar y expresarnos también a partir de imágenes que nos permitan proyectar un mundo nuevo.

Dentro de las posibilidades que nos otorgan las imágenes están las oportunidades de ocurrencia de la experiencia estética. Experiencias que a nuestro juicio se han quedado de lado y que deberíamos volver a instaurar desde la práctica escolar. Es decir, una experiencia integral que producida a partir de acontecimientos visuales y la posibilidades de trabajar con las imágenes, integre la creación y la crítica de las ideas de belleza, gusto y preferencia, aprendizajes sensoriales y conceptuales que nos permitan manifestar nuevas ideas, con aproximaciones sensoriales y apropiaciones de sentido.

La educación tiene la tarea de ampliar su horizonte epistemológico e imaginativo, disponer de los saberes interdisciplinarios que estudian el iconismo y la educación visual, y ampliar la enseñanza por medio de la imagen 
hacia una enseñanza de o para la imagen, evitando que sea "brutalmente normativa”. (Goyes, 2012, p. 145)

La educación artística asume esta tarea y genera oportunidades a partir de experiencias individuales que surgen de la experiencia estética, considerando aquellos espacios de relación en lo que aparentemente particular pueda ser transformado en una experiencia en común,de cuyas posibilidades de representación y significado podamos valernos para construir nuestra manera de ver el mundo y las acciones cotidianas que generamos en consecuencia.

Como premisa conceptual para las prácticas escolares es necesario evitar la tendencia homogenizante que la institución educativa impone en muchas ocasiones y pensar en las posibilidades de la diversidad, trabajando desde el reconocimiento de la heterogeneidad como una condición propia teniendo en cuenta que una clase escolar es un grupo de personas con experiencias, intereses e historias con diversas posibilidades; debemos apreciar y utilizar a favor de la igualdad de oportunidades más que de los resultados; debemos tener en cuenta los procesos con una final puesta en común de los trabajos elaborados en los talleres o en el aula y la necesidad de buscar acuerdos, pero también de expresar diferencias, lo que habrá de permitir a los estudiantes mayores oportunidades de construir sus miradas particulares y, a la vez, sentir la necesidad de articularlas con sus compañeros. Reconocer el valor del espacio de la educación artística y reivindicarlo en el currículo escolar, nos permite hacernos cargo también de los múltiples lugares en que ocurre la oportunidad de lo estético en la escuela. En la institución educativa, tan acostumbrada a la fragmentación disciplinar, no es menor el punto de reafirmación de que la posibilidad de atravesar experiencias estéticas no se limita el mundo de aquello que podamos definir como artístico y dado que la experiencia estética es necesariamente subjetiva, no puede construirse fuera de las relaciones personales, y es ésta una condición que debemos tener en cuenta cuando nos planteamos la acción educativa mediante la educación artística en el aula.

Tampoco debemos olvidar como lo señala María Acaso (2009) que a partir del hiperdesarrollo de la imagen, vivimos dentro del mundo-imagen, en una serie de mundos visuales paralelos al mundo real, construidos a través del lenguaje visual y que influye en nuestras vidas más que la propia realidad, cambiando nuestros pensamientos y costumbres a través de ciertos patrones sugeridos por la publicidad, constituida como el elemento fundamental en las sociedades de consumo, utilizando imágenes idealizadas y cada vez más sugestivas con la intención de manipular y convencer al espectador. Tampoco debemos olvidar que la capacidad de absorber, de asimilar las imágenes e interpretar la información visual no es una capacidad innata en el ser humano, sino que es una habilidad que hay que aprender a desarrollar y por lo tanto la educación artística tiene mucho que ver, no tanto con la consolidación, sino con la desconsolidación del mundo-imagen en función de desarrollar la capacidad crítica de nuestra mirada y donde no solo se enseñe para la contemplación sino que se enseñe para la comprensión.

La imagen en la comunicación de masas fluye de diversas maneras en un mundo que demarca nuevos derroteros de desarrollos visuales a los cuales nos enfrentamos intentando culturalmente hacer de la imagen nuestro mejor instrumento; "las imágenes son las formas más inteligibles de aprendizaje que los niños puedan observar” (Comenius, citado 
por Díaz 2007, p. 20), estableciendo una relación de sentido que se construye entre el texto y la imagen.

\section{Las nuevas tecnologías y su implicación en la educación artística}

En esta época contemporánea de superproducción de la imagen, no podemos obviar el lugar de las nuevas tecnologías de la información y las comunicaciones como alternativa para la educación en general y en especial la educación artística. Ningún curriculum es verdaderamente efectivo sin contextualizar como lo explica Viktor Lowenfeld (1980), y en ese sentido la educación parece haber olvidado que el papel de la escuela en nuestra sociedad contemporánea ha cambiado y ésta ya no es el único lugar donde se viene a aprender. Las sociedades se transforman y el sistema educativo debe responder a las nuevas exigencias de nuestra sociedad apoyadas en las tecnologías digitales dado que se incorporan a paso muy lento

Sucede lo contrario en la aplicación de las nuevas tecnologías alas expresiones artísticas; estas se han multiplicado considerablemente en los últimos tiempos, contribuyendo a enriquecer y a reorientar los mecanismos técnicos empleados tradicionalmente durante siglos por los artistas.

El desarrollo de nuevos medios de expresión como el video-arte y la aplicación del computador en las nuevas expresiones artísticas, la interactividad y los dispositivos virtuales, muestran cómo la video imagen y la imagen numérica, terminan por sumarse a las instalaciones multimedia;los nuevos soportes como el CD-ROM, las redes informáticas, internet, se suman al gran impacto que causan las nuevas tecnologías sobre las diferentes manifestaciones artísticas y su influencia en la educación artística, como la pintura, el dibujo, el diseño, la danza, el teatro, el cine, la fotografía, la arquitectura, etc., afectando también a otras como la museografía y mostrando como éstas mutaciones artísticas contribuyen a las transformaciones en el campo social.

La técnica a través de la historia se ha constituido como uno de los aspectos claves para el desarrollo de toda actividad artística; arte y tecnología han sido inseparables en el desarrollo del saber hacer y en la complejidad del proceso de la creación, las técnicas no se han constituido como instrumentos neutros; han sido sometidas, a veces difícilmente a la voluntad del artista, revirtiendo en algunas ocasiones en un carácter contrario, representando cada vez más un desafío permanente, donde el artista trabaja a partir de determinados materiales, los estudia hasta dominarlos y consigue manejar su técnica; los interioriza hasta el punto de hacerlos invisibles al espectador, pudiendo también dejarlos visibles y exhibirlos como una especie de trofeo sobre la escena del arte.

A través de las nuevas tecnologías el estatuto mismo de la imagen parece ser modificado, ampliado al mismo tiempo que se encuentra perturbada la relación y el sentimiento de realidad que mantenemos con el mundo perceptivo.

La televisión y el computador junto con el desenfrenado avance de las comunicaciones y la telefonía celular, que cada vez ofrece mayores posibilidades de comunicación, incluyendo mensajería de voz y datos, fotografía, internet, etc. dan nacimiento a otras formas de arte y de comunicación; debido a su popularidad y el fácil acceso, los hogares son invadidos 
por estos medios que se convierten en parte del paisaje familiar; otra revolución comienza recientemente con gran riesgo de modificar más aun nuestra relación tradicional con el mundo y son los mundos virtuales,imágenes llamadas de síntesis, la inter-actividad, la participación del espectador, la puesta de un mundo de sensaciones sintéticas, lo mediático y el gran desarrollo del mundo de las comunicaciones; todo esto concurriendo en grandes aportes a la creación de un universo artificial que bien podría en el futuro remplazar nuestros antiguos modos de percepción.

El mundo de la imagen y los universos artificiales están a un paso de ser el futuro preponderante; las tecnologías de la comunicación también se convierten en una apuesta económica y política mundial de primer plano, sirviendo como soporte a las nuevas formas del arte, centrados sobre la sociedad y los medios de comunicación de masas en una especie de arte sociológico, arte sobre la red, museos virtuales, redes informáticas, sitios web, plataformas de educación virtual, etc.

Los nuevos dispositivos técnicos funcionan sobre modos de redes en la forma invisible y eficaz de ramificaciones, confundiéndose frecuentemente con los medios que los transportan (sentido, materia, órgano); éstos dispositivos se aligeran en los últimos decenios jugando un importantísimo papel consecuente cerca de los artistas, el desarrollo de la video-cámara doméstica, el progreso de la fotografía digital, la aparición de computadores domésticos más fáciles cada vez de manipular y accesibles a la mayor parte del público.

El video-arte, el arte por computador, la fotografía digital, las instalaciones multimedia, la imaginería numérica, los mundos virtuales, la inter-actividad, los CD-ROM de artistas, la música electrónica, las redes y el arte en internet, nos harán atravesar el conjunto de tecnologías de punta que han marcado el desarrollo de la segunda mitad del siglo XX el video-arte y el arte por computador aparecen en 1960, más tarde le seguirá la imagen 3D en los años 1970, es importante también recordar cómo después de la segunda guerra mundial nos encontramos con el Happening, el Performance y la instalación.

El proceso de renovación y evolución de los soportes tradicionales nos conduce al problema más importante y evidente en la comunicación actual, que consiste en la producción excesiva de información, tanto de la palabra como de la imagen, afectando comportamientos como: la lectura secuencial, el aumento del desinterés por la lectura en las generaciones más jóvenes, el consumo de imágenes de forma indiscriminada, el incontrolable número de horas frente al televisor, el exceso de videojuegos, el abuso y saturación en el uso de las redes sociales y el teléfono celular,entre otros.

Esto último apunta al verdadero objetivo que debe cumplir la educación visual mediante la educación artística: superar la simple consideración recolectora de la información de imágenes (siendo por otra parte una tarea previa, pero orientada más a la selección que a la simple acumulación), e ir hacia la consideración de planteamientos teóricos y metodológicos que nos permitan afrontar los fenómenos de innovación mencionados, asociados a la imagen.

Cuando advertimos acerca del conjunto de necesidades que pueden presentarse para establecer el sentido en este campo, no es posible pasar por alto el lugar de la tecnología en la construcción de la visualidad contemporánea, en las formas de mirar y de ver, sustentado en el lenguaje que utiliza las imágenes para trasmitir información independientemente del soporte en que se muestren. 
Por lo tanto la educación visual como parte de la educación artística en la escuela, debe proponerse como una alternativa desde la cultura visual; la actitud del docente ha de ser la de quien explora e indaga en las posibilidades que la tecnología ofrece teniendo en cuenta que estamos en la era digital y que nuestros alumnos han crecido en los medios tecnológicos. Adoptar una actitud propositiva frente a la oportunidad de transformar nuestros conocimientos didácticos, con la utilización de las diversas experiencias vinculadas a la producción y utilización de las imágenes desde el uso de las diversas tecnologías digitales, permite encontrar diversos puntos de análisis en el que el desarrollo pleno de la ciudadanía contemporánea necesita de la toma de conciencia respecto de la utilización de los recursos de las nuevas tecnologías, especialmente cuando se trata del arte y de la imagen visual. Por tanto, es preciso no sólo conocer, sino también modificar y construir nuevas situaciones, permitiendo el ejercicio de la apropiación tecnológica también en este campo.

De esta forma, las oportunidades para la función crítica de los educadores necesitan un ajuste a las nuevas modalidades, no solo para adaptarse a éstas, sino para encontrar posibilidades alternativas de incidencia en posiciones que cuestionen el sentido dominante, especialmente cuando se está tomando y desarrollando el modelo de un computador por niño,dirigido a la totalidad de la población escolarizada.

Desde este punto de vista, se puede propiciar la producción colectiva de las imágenes y su análisis crítico, y generar espacios de reconocimiento comunitario entre jóvenes localizados en diferentes lugares geográficos, identificando puntos de contacto, acercamiento y distancia en relación con una producción artística determinada, su lugar virtual de exposición y circulación, y sus contextos. Esto puede incluso proponer formas directas de contacto que hagan viable el intercambio de producciones referidas a los procesos particulares y personales de algún proyecto específico de alumnos, que trasciendan la institucionalidad escolar y procuren la autonomía de sus participantes.

Si por una parte es necesario promover las relaciones intersubjetivas que favorezcan aprendizajes individuales, éstos no pueden concebirse fuera de la relación conceptual y la acción creativa a partir de la manipulación de imágenes por distintos medios: las tecnologías de la información y la comunicación, el teléfono móvil, los computadores, las cámaras fotográficas, y su intervención en procesos de producción visual.

Parte de los interrogantes que podríamos despejar mediante estas prácticas están en la forma en que una imagen, una obra, una tecnología relacionada con lo visual ayuda a construir la experiencia a través de nuestros sentidos y la relación con el contexto; es testimonio de nuestra propia vida, permite que nos interrelacionemos con otros, nos hace partícipes de un colectivo, nos identifica, nos ayuda a entender el mundo y representa una oportunidad para transformar nuestro entorno.

\section{La imagen y el arte como referente en la educación artística}

Solamente a través de los sentidos puede tener lugar el aprendizaje (Löwenfeld - Lambert, 1980). Esta afirmación parece apenas obvia, pero no en nuestro sistema educativo que parece cada vez más alejarse de las experiencias directas, convirtiendo al estudiante en alguien pasivo, sin ninguna oportunidad a su intervención sensorial. En este sentido, 
afirma Rudolf Arnheim (1986) que la actividad artística llega a una mayor cabalidad de la comprensión de la percepción visual como actividad cognitiva, describiéndola como una forma de razonamiento en la que percibir y pensar son actos que se encuentran indivisiblemente entremezclados;afirma además, que una persona que pinta, escribe, compone o danza, piensa con sus sentidos y el pensamiento verdaderamente productivo en cualquiera de las áreas de la cognición, tiene lugar en el reino de la imaginería.

Esta similitud entre el papel que le corresponde a la imagen y a la mente en las artes, y el que le corresponde a los otros dominios sugiere la posibilidad de colocarse en una nueva perspectiva frente al abandono y el aislamiento al que se condenan las artes en la sociedad y la educación. Así mismo Löwenfeld en su libro El desarrollo de la capacidad creadora"(1980) destaca la importancia del arte en la educación, considerándola como una actividad dinámica y unificadora con un rol potencialmente vital en la educación de nuestros niños, afirmando que el arte mediante sus distintas manifestaciones le permite reunir diversos elementos de su experiencia para conformar un todo con un nuevo significado, a través de los nuevos elementos el niño puede expresarse proporcionándonos una parte de sí mismo.

No deberíamos dejar de considerar que la escuela es hija de la imprenta y aliada del texto escrito, y que esta asume una actitud de sospecha ante las actividades artísticas, a las que considero destinadas básicamente a la distracción o entretenimiento. Es importante tener presente que Occidente ha privilegiado de forma sistemática a la cultura letrada, considerándola como la más alta forma de práctica intelectual; en cambio califica como de segundo orden, empobrecidas, a las representaciones visuales.

Nuestro sistema educativo actual asigna mucha importancia al aprendizaje de la correcta información acerca de hechos, dándole importancia a la memorización y ala capacidad de recordar fragmentos de información que el maestro conoce muy bien, de tal manera que la función de la educación parece reducirse a formar gente capaz de reproducirla una vez exigida esta información, pero esta habilidad muchas veces puede tener muy poca relación con aquello que realmente se debería haber formado y muchas veces sin ninguna relación con el contexto social, restando importancia a las habilidades básicas que se deberían enseñar como la autonomía y la actitud crítica, la habilidad de explorar y descubrir, de encontrar nuevas formas y nuevos ordenes, de volver a pensar, de reestructurar y encontrar nuevas relaciones, de buscar respuestas, de indagar, de experimentar y comprobar. Son cualidades que generalmente no se enseñan y pareciese que en nuestro sistema educativo no se tienen en cuenta. Las experiencias fundamentales en una actividad artística contienen precisamente estos factores.

Solamente a través de los sentidos puede tener lugar el aprendizaje, estos son los canales de información que nutren directamente nuestro cerebro para dotarnos de experiencias, pero parece que nuestro sistema cada vez confía menos en el contacto real con el medio, convirtiéndose en un actor pasivo antes que en constructor activo, nuestra educación hace muy poco por educarlos y parece alejarse cada vez más de esa posibilidad de poder tocar, ver, oír, oler y saborear como actividad participativa del individuo como experiencia de aprendizaje significativo. La educación artística como alternativa para suplir esta urgente necesidad es la única disciplina que permite este tipo de experiencias ya que se concentra en las experiencias sensoriales, permitiendo desarrollar la sensibilidad auditiva que 
significa escuchar con atención no simplemente oír, tener sensibilidad visual que implica captar diferencias y detalles en tamaños, formas, espacio, texturas y colores, no solamente el hecho de reconocer una forma, y lo mismo podría decirse de cada uno de los demás sentidos a través de la experiencia sensorial.

La educación artística compromete varios aspectos: lo visual, la plástica, la auditiva, la cinética, la verbal y la constructiva; pero su propósito final es procurar que cada ser humano se exprese desde su propia esencia y sea capaz de armonizarla con su grupo social o comunidad a la que pertenece abarcando los cambios sociales, intelectuales, emocionales y psicológicos que operan en el individuo.

Si el arte como decía Hegel actúa como fuerza moralizadora, como potencia purificadora de las pasiones, como sentimiento concentrado en sí mismo que se objetiva en las representaciones artísticas, puede inferirse que el abordaje del arte en todas sus dimensiones significa sublimar la naturaleza humana transfiriéndole condiciones particulares. Bajo tales reflexiones, la enseñanza del arte a través de la educación artística, no puede ni debe poseer la voluntad del aprendiz, sino procurar develar sus propias posibilidades, desde las cuales contará con herramientas para entender el mundo. Las manifestaciones artísticas a través de la historia revelan la evolución del pensamiento y el carácter ambicioso de la especie; ellas son los entes reveladores de la cultura.

La enseñanza a través del arte tiene hoy una reconfiguración a partir de un nuevo intento de suspensión de las diferencias entre los procedimientos, estrategias y fines de la cultura. Su reforma y modernización deben pretender la promoción de un movimiento generador de fuentes de proyección artística en la esfera social. Para ello la actividad docente debe incorporarse al ritmo y transformación de las metodologías planteadas por las más notables prácticas artísticas de las últimas décadas y sus condicionantes sociales sobre la acogida y entendimiento de la obra de arte.

En consecuencia, la imagen a través de la educación artística debe promover y posibilitar el desarrollo del potencial de la práctica artística como referente del más significativo don de la existencia humana, el lenguaje del arte. Para ello, el espacio creado a través de la educación artística, propende por mantener docentes cuyas metodologías sean fundamento de participación de proyectos colectivos acordes con las demandas de las últimas décadas, que propicien el desarrollo y la innovación en cada estudiante permitiéndole ser actor principal en la transformación de su entorno y su integración al medio cultural y social.

\section{Conclusiones}

Según Bauman (2007) la educación en épocas pasadas respondió a los desafíos de las cambiantes circunstancias sociales, ajustándose a sus necesidades, fijándose nuevos objetivos y estrategias. Pero el cambio actual no es como el pasado, en ningún otro punto de inflexión de la historia los educadores debieron de afrontar un desafío como el que nos presenta la época contemporánea ya que nunca antes estuvimos en una situación semejante, donde aún debemos aprender el arte de vivir en un mundo sobre saturado de información y también debemos aprender el más difícil arte de preparar a la próximas generaciones para vivir en semejante mundo. 
En este reto del que habla Bauman, los que nos dedicamos a la enseñanza aprendizaje, debemos acometer este desafío, especialmente en las disciplinas relacionadas con las artes y la cultura visual porque nuestro contexto está sobresaturado de información y la mayoría de esa información es información visual.

Se valida de este modo el hacer y quehacer de la educación artística desde los primeros años de vida dado que "los medios y la exploración de técnicas", son el pretexto ambiental para que el niño, desde su experiencia subjetiva, acuda gustoso al encuentro con el mundo y logre plasmar lo que percibe, permitiéndonos afirmar que la expresión artística es una excelente herramienta educativa que nos ayuda a conocer y saber más acerca de lo que piensan y sienten los niños, lo que apunta, entre otras cualidades, a su desempeño como personas autónomas con capacidades diferentes.

Los documentos investigados sobre los conceptos de ver y mirar aplicados, el lenguaje y comunicación visual, la lectura y análisis de imágenes a través de diferentes medios como: fotografía, cine, televisión, internet, vídeo digital, redes sociales, las artes y la cultura y el lugar que las imágenes desempeñan dentro de nuestra sociedad, nos permiten desarrollar a través de la educación artística una cultura visual.

Generalmente nuestra percepción de las imágenes se da de manera más intuitiva, que nos hace placentera o molesta una imagen o una sucesión de imágenes. El ejemplo más contundente es la imagen poética o la artística, que apela a la percepción estética, cualidad que si bien puede considerarse innata en el ser humano, se desarrolla por la educación a lo largo de la vida del individuo.

Hoy en día la actividad docente requiere de mayor dinamismo, los maestros debemos permanecer en constante actualización, no podemos seguir enseñando como nos enseñaron, porque son nuevas generaciones con nuevos conocimientos y otras realidades sociales, nuevos valores, nuevas formas de construir conocimiento.

La educación artística y el desarrollo de una cultura visual contribuyen a una formación integral de los individuos a partir del aporte que realizan las competencias específicas como la sensibilidad, la apreciación estética y la comunicación. El desarrollo de las competencias básicas también se logra a través de la experiencia vivenciada por los estudiantes en la realización de diversos procesos pedagógicos y su interacción con los contextos que son propios de las artes y la cultura.

Se evidencia la necesidad de un proceso en el que se plantee la capacitación de nuestros alumnos hacia una didáctica de la imagen,mediante la educación artística, derivada de la importancia que en la sociedad actual se concede al mundo de lo icónico; una didáctica que desarrolle el lenguaje de la imagen con el fin de familiarizara los alumnos que diariamente están expuestos desde los distintos soportes tecnológicos con los elementos, códigos y principios básicos que la imagen explota, posibilitando y promoviendo estrategias para su lectura crítica y comprensiva.

\section{Bibliografía citada}

Acaso María. (2009) La Educación Artística no son Manualidades. Madrid. Catarata. 
Aguadedgómez, J.I. (1993)Comunicación audiovisual. Huelva, Grupo Pedagógico Andaluz "prensa y educación".

Alonso, M. y Matilla, L. (1990) Imágenes en acción: Análisis y práctica de la expresión audiovisual en la escuela activa. Madrid, Akal.

Arnheim, Rudolf. (1966). Arte y Percepción Visual. Barcelona: Alianza Forma.

Arnheim, Rudolf.(1971) El Pensamiento Visual. Buenos Aires. Paidós.

Bauman. Z (2007) Los retos de la educación en la modernidad liquida. Barcelona. Gedisa.

Bousquet, Patrick. (1980)Jaffrennou, J. M. Vidéothéâtrie et autres formes vidéo. Paris :Labyrinthe.

Blazquez, F.(1983) La imagen como recurso didáctico”, en Didáctica General de Sáenz, O. y Otros, Madrid, Anaya.

Cabanne, P. (1972) Conversations con Marcel Duchamp. Barcelona. Anagrama.

Díaz, F. H (2008) Leer y mirar el libro álbum: ¿un género en construcción?Bogotá. Norma Dondis, D. A (1976) La Sintaxis de la Imagen. Barcelona: Gustavo Gili.

Duchamp, M. (1989) Notas. Madrid. Technos.

Duguet Anne Marie. (2002) Déjeuner l’image. Nîmes. Jacqueline Chambón.

Eco Humberto, (1992) Los límites de la interpretación. Barcelona. Blume.

Forest Fred, (2004) De L'Art Vidéo... Au Net Art. Art Sociologique et Esthétique de laCommunication, Paris. L'Harmattan.

Florence de Meredieu, (1981) Télévision la lune. Paris : Des femmes. Paris. Larousse.

Florence de Meredieu (2005) Arts et nouvellestechnologies. Des femmes. Paris. Larousse.

Gibson, J .J. (1974) La percepción del mundo visual. Buenos Aires. Infinito.

Guillaume, P. (1971) Psicología de la forma. Buenos Aires: Psique.

Gombrich, E. H. (1979) Arte e ilusión. Barcelona: Gustavo Gili.

Gombrich, E. H (1983)Arte, percepción y realidad. Barcelona. Paidós.

Goyes Julio Cesar, (2012) La imaginación poética. Caza de libros, Ibagué Colombia.

Grenie Catherine. (2008) La Revanche des Emotions. Paris. de Senil.

Kandisky, W. (1973)De lo Espiritual en el Arte, Barcelona. Eblace.

Kisseleva Olga, Cyberart, (1998)Un essai sur l'art du dialogue. Paris: L'armattan.

Lipovetsky, G. (2007) La felicidad paradójica. Ensayo sobre la sociedad de hiperconsumo. Barcelona. Anagrama.

Lowenfeld Viktor- Brittain Lambert (1980) El desarrollo de la capacidad creadora. Madrid. Kapesz.

Marshall, Macluhan. (1968) Pourcomprendre les media. Paris. Seuil.

Moles, Abraham. (1970) Art et ordinateur. Paris. Casterman.

Ortega Y Gasset. (1984)La Deshumanización en el arte. Madrid. Alianza.

Ortega, J. A. y Otros (1996) Alfabetización visual y desarrollo de la inteligencia. Granada, Fundación.

Panofsky, E. (1979) El significado de las artes visuales. Madrid. Alianza Forma.

Pierre, j .(1968) El futurismo y el Dadaísmo, Madrid. Aguilar.

Red Herbert, (1982) Educación por el arte. Barcelona. Paidós.

Sedmayer, H. (1959) El Arte Descentrado. Barcelona. Labor.

Wingler,H.M. (1968) Las Escuelas de Arte de Vanguardia. 1900-1993 Buenos Aires. 


\section{Bibliografía recomendada}

Alonso, M. y Matilla, L. (1980): Imágenes en libertad. Madrid, Nuestra cultura.

Aparici, R. (1987): Lectura de imágenes. Madrid, De la Torre.

Baril, Stéphane \&Naits. (2005) Colorisation de BD du traditionnel au numérique. Paris. Eyrolles.

Calvo Serraller, F. (1987) Imágenes de lo insignificante. Madrid. Cátedra.

Davies, Lancasterr y Scott. (1984). Pintar y Dibujar. Madrid. Ceac.

Daucher, H. (1987) Modos de dibujar. Barcelona. Gustavo Gili.

De Micheli, (1983) Las vanguardias artísticas del siglo XX. Milán. Alianza Forma.

Gómez Molina, JJ (Coord.) Y Otros (1995): Las lecciones del dibujo. Madrid. Cátedra.

Gregory, R. (1969) Ojo y cerebro, Psicología de la visión. Madrid. Guadarrama.

Guerin Michel. (2003) Nihilisme et Modernité, Essai sur la Sensibilité des Epoques Modernes de Diderot à Duchamp. Nîmes. Jacqueline Chambou.

KurstHanks Y Larry Belliston, (1995) El dibujo, La imagen como medio de Comunicación. México: Trillas.

Martín, M. (1987) Semiología de la imagen y pedagogía. Madrid, Narcea.

Puente, R. (1986) Dibujo y Educación Visual. México.

Rainwater, C. (1976) Luz y Color. Barcelona: Daimon.

Rubio, O. M. (1994) La Mirada interior: El surrealismo en la Pintura, Madrid. Tecnos.

Schlosser, J. (1976) La Literatura Artística. Madrid. Cátedra.

Summary: The article explains the various effects produced by the current world saturated with images. From the characterization, displays different concepts to enhance teaching and learning through the use of the image.

Key words: image - visual education - critical sense.

Resumo: $\mathrm{O}$ artigo analisa os diferentes efeitos que produze o atual mundo saturado de imagens. A partir da caracterização, desdobra diferentes conceitos para potenciar o ensino-aprendizagem através do uso da imagem.

Palavras chave: imagem - educação visual - sentido crítico. 